\title{
ACCIÓN COLECTIVA DE LAS MUJERES Y PROCESOS EMANCIPADORES EN AMÉRICA LATINA Y EL CARIBE. UNA APROXIMACIÓN DESDE LOS CASOS DE CUBA, BOLIVIA Y ECUADOR
}

Iratxe Perea Ozerin

\section{INTRODUCCIÓN}

En este artículo se trata la participación de las mujeres organizadas en movimientos y procesos emancipadores. Esta cuestión ha sido investigada en el ámbito de las Relaciones Internacionales mediante estudios de caso y política comparada, destacando su aplicación en el contexto latinoamericano. ${ }^{1}$ Siguiendo esta línea de estudio, proponemos aquí un marco teórico que permita profundizar en la efectividad de esta participación en procesos con características diferentes en cuanto a las formas de participación de los actores sociales y la naturaleza de los movimientos de mujeres implicados. Para ello, proponemos una aproximación comparativa a los casos

${ }^{1}$ Véase M. Molyneux, "Mobilization without emancipation? Women's interests, the state and revolution in Nicaragua”, Feminist Studies, vol. 11, núm. 2, 1985, pp. 227-254; Molyneux, Movimientos de mujeres en América Latina. Estudio teórico comparado, Madrid, Cátedra, 2003; J. S. Jaquette, "Women in Revolutionary Movements in Latin America", Journal of Marriage and the Family, vol. 35, núm. 2, 1973, pp. 344354; Jaquette, "The Women's Movement in Latin America: Feminism and the Transition to Democracy”, Bulletin of Latin American Research, vol. 9, núm. 2, 1990, pp. 291-293; Jaquette (ed.), The women's movements in Latin America. Participation and democracy, Boulder, Westview Press, 2ª ed., 1994; S. Álvarez, Engendering democracy in Brazil. Women's movements in transition politics, Princeton, University Press, 1990. 
de la Revolución cubana, por un lado, y los recientes procesos constituyentes de Bolivia y Ecuador, por otro. Aunque debemos tener en cuenta la gran diferencia entre Cuba y Ecuador y Bolivia, en lo que atañe a los periodos abarcados, las dos legislaturas tras los procesos constituyentes permiten evaluar, en cierta medida, la orientación tomada respecto a la política de género.

La hipótesis de partida es que incluso en procesos de estas características, como afirma Maxine Molyneux, es más fácil lograr avances en igualdad de género en los ámbitos jurídico y político que en el de los derechos económicos y sociales, los cuales permitan una transformación real de las vidas de las mujeres. ${ }^{2}$

Respecto a la estructura del artículo, en primer lugar definimos los principales elementos del estudio: qué entendemos por movimientos de mujeres y procesos emancipadores, qué tipologías de movimientos de este tipo hay en el contexto latinoamericano y cómo se evalúa la efectividad de las diferentes formas de participación de las mujeres en procesos emancipadores. En segundo, estudiamos los casos citados con base en este marco teórico y aportamos las conclusiones del estudio.

La metodología empleada consiste fundamentalmente en la investigación bibliográfica desde una perspectiva internacionalista y sociohistórica. Cabe señalar que la autora no escribe desde los contextos analizados, por lo que, sobre todo en el caso de la investigación empírica, aunque también en el diseño del marco teórico, se ha basado en fuentes procedentes de estos contextos y en voces allí presentes, tanto oficiales como académicas, periodísticas y de la sociedad civil.

LA ACCión COLECTIVA DE LAS MUJERES

eN AMÉrica Latina y El CARIBE

\section{Definiciones}

Para este estudio resulta adecuado el término Acción Colectiva de las Mujeres (АСM) empleado por Maxine Molyneux, que engloba

${ }^{2}$ Movimientos..., p. 314 . 
la gran diversidad de movimientos de mujeres que se han articulado en América Latina y el Caribe. ${ }^{3}$ Otras definiciones de movimientos de mujeres, como la de Sonia Álvarez, ${ }^{4}$ excluyen grupos de mujeres como los organizados dentro de movimientos y procesos mixtos, que en este artículo cobran particular relevancia.

El concepto de ACM engloba de un modo más amplio lo que Sheila Rowbotham denominó "mujeres en movimiento", ${ }^{5}$ e incluye ese feminismo descrito por la feminista indígena Julieta Paredes: "Toda acción organizada por las mujeres indígenas en beneficio de una buena vida para todas las mujeres, se traduce al castellano como feminismo". ${ }^{6}$ Paredes aporta otra definición igualmente amplia en su libro sobre feminismo comunitario: "feminismo es la lucha y la propuesta política de vida de cualquier mujer en cualquier lugar del mundo, en cualquier etapa de la historia, que se haya rebelado contra el patriarcado que la oprime". ${ }^{7}$ Sin embargo, es crítica con la acepción de feminista para cualquier movimiento de mujeres organizadas. Sostiene que las mujeres misóginas y lesbofóbicas dentro de estos movimientos no pueden estar haciendo feminismo. Las definiciones de feminismo, afirma, deben provenir de una postura crítica ante la misoginia colectiva. ${ }^{8}$

A la hora de definir procesos emancipadores, se considera adecuada la definición de Fred Halliday, quien habla de "grandes transformaciones políticas y sociales en el contexto de una modernidad contradictoria, que suponen una participación de masas y una aspiración a establecer una sociedad radicalmente diferente". ${ }^{9}$ Si bien Halliday se refiere a revoluciones, como puede ser la cuba-

${ }^{3}$ Ibidem, p. 227.

${ }^{4}$ Op.cit., p. 23.

${ }^{5}$ Women in movement. Feminism and social action, Londres, Routledge, 1992.

${ }^{6}$ Idea expresada a Francesca Gargallo y recogida en su libro Feminismos de Abya Yala. Ideas y proposiciones de las mujeres de 607 pueblos en Nuestra América, México, Editorial Corte y Confección, 2014, p. 21.

${ }^{7}$ Hilando fino desde el feminismo comunitario, La Paz, Mujeres Creando Comunidad-Deutscher Entwicklungdienst, 2010, p. 7.

${ }^{8}$ En Gargallo, op.cit., p. 183.

${ }^{9}$ Revolution and world politics. The rise and fall of the sixth great power, Hampshire, Palgrave Macmillan, 1999. 
na, consideramos que esta definición puede aplicarse a otro tipo de procesos de contestación social, ${ }^{10}$ como en los casos de Ecuador y Bolivia. En ambos procesos, se articuló un amplio movimiento político-social contra los gobiernos previos, con una importante participación de la ciudadanía en las constituyentes y una aspiración inclusiva y transformadora.

\section{Tipologías}

Según sus formas de organización, en el caso latinoamericano pueden distinguirse tres tipos de ACM:

i) Movimientos independientes o autónomos: tienen control pleno de su agenda.

ii) Tejido asociativo: hacen alianzas con otras organizaciones políticas. Buscan la negociación desde un mandato autónomo, mientras que las otras organizaciones deben integrar sus reivindicaciones en cierta medida.

iii) Movilizaciones dirigidas: hay una autoridad externa que controla estos colectivos, en algunos casos sin una agenda feminista definida y en otros con un proyecto emancipador universal del que forma parte específica la emancipación de las mujeres. ${ }^{11}$

Al mismo tiempo, el surgimiento y evolución de la ACM en Latinoamérica ha estado definida por el contexto sociohistórico de la región. Destacan tres tipos de procesos históricos que han influido en la articulación de la ACM: la colonización y el neocolonialismo, las dictaduras militares y regímenes autoritarios y las crisis socioeconómicas.

Teniendo esto en cuenta, Gina Vargas distingue principalmente tres corrientes: ${ }^{12}$

${ }^{10}$ I. Perea Ozerin, Incidencia de las Revoluciones en los Movimientos Sociales Transnacionales. El caso de la Revolución Cubana y su influencia en el Movimiento Antiglobalización, tesis, Leioa, Universidad del País Vasco/Euskal Herriko Unibertsitatea, 2014, p. 76.

${ }^{11}$ Molyneux, Movimientos..., pp. 227.-235.

12 "El movimiento de mujeres en el Perú: vertientes, espacios y nudos", en Feminismos en América Latina. Su aporte a la política y a la democracia, Lima, Programa 
i) La corriente feminista o el feminismo tradicional: ha tenido un recorrido similar al movimiento feminista internacional. ${ }^{13}$ Los primeros grupos feministas surgieron en el siglo xIX y estaban formados por activistas de clase media y alta. Desde esa corriente se reivindicó fundamentalmente la igualdad en el espacio público. Se identifica en sus inicios con un feminismo de la igualdad. Sufrió un auge a principios del siglo xx con las luchas por el sufragio femenino, la ley del divorcio, educación para las mujeres e incorporación de las mujeres en cargos públicos. Y volvió a tener fuerza con la Década de la Mujer de Naciones Unidas (1975-1985), con una creciente orientación hacia el feminismo radical y el estudio del ámbito privado como origen del patriarcado. En cuanto a formas de organización, se trata generalmente de movimientos autónomos o asociativos.

ii) La corriente popular o el feminismo social: ha estado unida a la defensa de los medios de vida y la lucha se ha llevado a cabo desde los roles de género de las mujeres (madres o esposas). Pueden mencionarse la participación de las mujeres en las luchas de los mineros en Perú y Bolivia, el caso notable de las Madres de la Plaza de Mayo en Argentina o las luchas de colectivos del catolicismo social. Cobraron fuerza en los años setenta con la crisis del petróleo y en la "década perdida" de los años ochenta. En el contexto de conflictos armados, por ejemplo en Nicaragua o Colombia, también se ha articulado АCM de este tipo. Y más recientemente para denunciar la violencia contra las mujeres en México y Guatemala, con respecto de los casos de Ciudad Juárez y otras situaciones de extrema violencia en las fronteras de estos países. Según Molyneux, la relevancia de los movimientos de mujeres populares en esta región ha llevado al auge de un "feminismo social". ${ }^{14}$ Las reivindicaciones sociales colectivas gozan de una amplia proyección y de una amplia participación popular.

Democracia y Transformación Global, Centro de la Mujer Peruana Flora Tristán y UNMSM, 2008, pp. 32-92.

13 M. Fuentes, "Feminismo y movimientos populares en América Latina", Nueva Sociedad, núm. 118, 1992, pp. 55-60.

14 Movimientos..., p. 269. 
Cabe incluir aquí corrientes con protagonismo propio, aunque muy relacionadas con este feminismo popular, como el "feminismo comunitario" y el "feminismo indígena", que recientemente han ganado visibilidad con aportaciones relevantes de las mujeres xinkas de Guatemala y aymaras de Bolivia. Este auge tiene que ver con el protagonismo de las luchas indígenas, sobre todo, en los años noventa. ${ }^{15}$ Y descuellan como una aportación propia desde el feminismo latinoamericano. ${ }^{16}$ Esta corriente tiende hacia una forma de organización autónoma, especialmente en el caso del feminismo comunitario, o asociativa.

iii) La corriente militante: se ha formado de las mujeres que participaron en organizaciones de izquierda como sindicatos, movimientos de liberación nacional, partidos políticos, etc. ${ }^{17}$ Destacaron en los principales procesos revolucionarios del continente, entre ellos la Revolución mexicana (1910), la Revolución cubana (1959) o la Sandinista en Nicaragua (1979). ${ }^{18}$ En algunos casos, la falta de representación de las mujeres en estos movimientos y la no incorporación de sus demandas llevaron a que se establecieran comisiones de mujeres en esas organizaciones. En otros, las mujeres militantes pasarían a formar parte de organizaciones autónomas. En cuanto a la organización, en esta corriente predominan los movimientos dirigidos.

Cabe señalar que las corrientes de ACM citadas han trabajado de forma conjunta. Ya en el siglo XIX organizaciones feministas participaron en las luchas por la independencia. También se dieron convergencias a principios del siglo $\mathrm{xx}$, unidas a un auge de todas las corrientes, durante la Década de la Mujer de Naciones Unidas (1975-1985) ${ }^{19}$ y al hilo de las movilizaciones contra la globalización neoliberal de los años noventa y la década de los $2000 .{ }^{20}$

${ }^{15}$ Gargallo, op. cit., pp. 151-196.

16 A. Cabezas González, "Anotaciones sobre el tejido feminista latinoamericano: más allá de las genealogías”, Contextualizaciones Latinoamericanas, año 6, núm. 11, 2014, p. 2.

17 Vargas, "El movimiento de mujeres...".

18 Jaquette, "Introduction: from transition to participation..., p. 2.

${ }^{19}$ Fuentes, art. cit., pp. 55-60.

${ }^{20}$ I. Perea Ozerin, "El papel del feminismo en el Movimiento Antiglobalización: contribuciones y desafíos", Revista CIDOB d'Afers Internacionals, núm. 105, 2014, pp. 67-88. 


\section{Criterios de evaluación}

Para valorar la efectividad de las luchas de las mujeres por lo que toca a la política de género implementada en estos procesos, empleamos la definición de Nancy Fraser de la lucha feminista por la justicia. Fraser distingue tres elementos que se combinan en esta lucha: reconocimiento, representación y redistribución. ${ }^{21}$ Sin ánimo de profundizar aquí en el desarrollo teórico-conceptual de Fraser, se utilizan las tres dimensiones que propone como herramienta analítica para la evaluación de los logros y limitaciones de la participación de los movimientos de mujeres en la Revolución cubana y los procesos constituyentes de Bolivia y Ecuador.

La primera dimensión, el "reconocimiento", se relaciona con el ámbito cultural y la lucha desde el feminismo contra el androcentrismo que caracteriza a la sociedad patriarcal. En este sentido, observamos aquí la incorporación de la perspectiva de género y la teoría feminista a los cimientos jurídicos y políticos del proceso en cuestión. Se examinan las políticas derivadas del análisis feminista, en particular sobre dos aspectos clave: violencia contra las mujeres y derechos sexuales y reproductivos.

La "representación" se refiere al ámbito político y la escasa presencia histórica de las mujeres en el mismo. Se examina, en este caso, la participación efectiva de las mujeres en la política y los centros de decisión principales, así como la aplicación de cuotas y políticas de paridad en el diseño de los órganos de gobernanza.

Finalmente, la "redistribución" se relaciona con el ámbito socioeconómico y la perspectiva de la economía política feminista. La analizamos tanto respecto al ámbito productivo como al reproductivo.

Como decíamos, Molyneux sostiene que en la lucha feminista ha sido tradicionalmente más fácil lograr avances en cuanto a igualdad en el ámbito jurídico y político, relacionados con el reconocimiento

${ }^{21}$ Fortunes of feminism. From state-managed capitalism to neoliberal crisis, Londres, Verso, 2013, pp. 1-5. 
y representación, que en lo atinente a logros socioeconómicos relacionados con la redistribución. ${ }^{22}$

\section{LA EMANCIPACIÓN DE LAS MUJERES EN LA REVOLUCIÓN CUBANA}

El recorrido del movimiento feminista en Cuba fue similar al latinoamericano durante las primeras décadas del siglo xx e incluso se ha considerado a Cuba como pionera en la construcción de espacios feministas. ${ }^{23}$ Tras el golpe de Estado del general Fulgencio Batista, en 1952, la lucha de las mujeres se incorporó al frente contra la dictadura. Organizaciones como el Frente Cívico de Mujeres Martianas, que, en 1955, pasaron a formar parte del Movimiento 26 de Julio de Fidel Castro, y las Mujeres Opositoras Unidas, integrada por militantes del Partido Socialista Popular (PSP), desempeñaron un importante papel en la insurgencia. Asimismo, tanto en las guerrillas rurales como en los operativos urbanos hubo una participación destacable de las mujeres. ${ }^{24}$ Pero sus reivindicaciones feministas pasaron a un segundo plano, supeditadas a la lucha contra la dictadura. El sector intelectual que esencialmente conformaba el movimiento de principios del siglo xx dio paso a organizaciones de mujeres de base identificadas con la Revolución, que a partir de 1960 se integraron en la Federación de Mujeres Cubanas (FMC).

Desde entonces, la FMC ha encabezado las políticas dirigidas a la emancipación de las mujeres y la lucha contra la discriminación por género. Como entidad dependiente del Estado, entraría en la tipología de movimiento dirigido según la forma de organización y de la corriente militante dados sus rasgos sociohistóricos. Con el triunfo de la Revolución el feminismo de carácter liberal-burgués que existía a principios del siglo xx en Cuba fue rechazado como parte de la crítica a la jerarquía de clases. La FMC se alejó de esta

${ }^{22}$ Movimientos..., p. 314.

${ }^{23}$ N. Vasallo Barrueta, Ecos distantes, voces cercanas, miradas feministas, La Habana, Editorial de la Mujer, 2012, pp. 69-74.

${ }^{24}$ J. Macías Amores, La sociedad civil en la Revolución cubana (1959-2012), Leioa, Universidad del País Vasco/Euskal Herriko Unibertsitatea, 2016, pp. 256-257. 
concepción del feminismo y este término aún se rechaza. ${ }^{25}$ La que fue presidenta de la FMc, Vilma Espín, achacó este rechazo a su asimilación con algo foráneo y propio del capitalismo. ${ }^{26}$ Según Molyneaux, en este contexto la función como organismo gubernamental ha dotado de poder a la FMC, pero al mismo tiempo ha socavado su autonomía, impidiéndole hacer reflexiones independientes de las orientaciones del gobierno. ${ }^{27}$

\section{Reconocimiento}

A lo largo del periodo revolucionario la teoría y la práctica feminista tal y como evolucionaron a nivel internacional no se han llegado a incorporar al socialismo cubano. En el periodo de mayores transformaciones revolucionarias en Cuba, entre los sesenta y setenta, en un contexto de auge del denominado "feminismo radical", se daban reflexiones y debates sobre el patriarcado, el origen de la violencia y discriminación hacia las mujeres en el ámbito privado, y se impulsaban campañas por el reconocimiento económico del trabajo doméstico. ${ }^{28}$ Sin embargo, las políticas de género en Cuba han tenido como base ideológica el proyecto de transformación socioeconómico más amplio impulsado por la Revolución.

${ }^{25}$ E. Dixie, "Cuba: feminismo sin etiqueta”, Feminismo en Cuba, 20 de diciembre de 2010 .

${ }^{26}$ I. Moya, "Alas desatadas", Intervención en el Seminario 50 Aniversario de la Revolución Cubana celebrado en La Habana, del 14 al 16 de julio de 2008, disponible en La Jiribilla, 3-9 de enero 2009.

27 Movimientos..., pp. 126-131 y 148-153.

${ }^{28}$ A. H. Puleo García, "Lo personal es político: el surgimiento del feminismo radical”, en A. de Miguel Álvarez y C. Amorós Puente (eds.), Teoría feminista: de la ilustración a la globalización. Del feminismo liberal a la posmodernidad, Madrid, Minerva Ediciones, 2010, pp. 38-42; I. Rodríguez Manzano, "Mujer, género y teoría feminista en las Relaciones Internacionales", en Cursos de Derecho Internacional y Relaciones Internacionales de Vitoria-Gasteiz 2000, Leioa-Madrid, Universidad del País Vasco/Euskal Herriko Unibertsitatea-Tecnos, 2001, pp. 282-283; S. Federici, "Salarios contra el trabajo doméstico" (1975), en S. Federici, Revolución en punto cero. Trabajo doméstico, reproducción y luchas feministas, Madrid, Traficantes de Sueños, 2013, pp. 35-44; y S. Federici y N. Cox, "Contraatacando desde la cocina" (1975), en ibid., pp. 51-70. 
La directora de la Editorial de la Mujer y de la revista Mujeres de la FMC, Isabel Moya, señala que se abordó desde el principio del proceso la discriminación hacia las mujeres como una problemática sujeta a la aplicación de políticas concretas. ${ }^{29}$ Estas políticas se enmarcaron en la lucha del gobierno revolucionario contra todo tipo de discriminación por clase, etnia o sexo. ${ }^{30} \mathrm{El}$ socialismo cubano estableció como objetivos fundamentales la eliminación de todas las formas de discriminación contra las mujeres y su incorporación a todos los ámbitos de la vida pública, al contar con la FMC como agente fundamental para esta tarea. Con esta organización también se ha impulsado la participación de las mujeres en la construcción de una sociedad socialista en Cuba. ${ }^{31} \mathrm{Al}$ parecer de Maxine Molyneaux, como parte de su compromiso con la igualdad y la justicia social, "el socialismo cubano promovió la igualdad ante la ley, consiguió una mayor incorporación de las mujeres a la esfera pública y fue el único estado latinoamericano que garantizó sus derechos reproductivos". ${ }^{32}$

En efecto, el respeto a los derechos reproductivos de las mujeres cubanas se cuenta entre los principales logros feministas de la Revolución, si tenemos en cuenta que representa el primer país latinoamericano donde el aborto es legal y gratuito (desde 1965). También cabe señalar en este sentido el trabajo que ha realizado el Centro Nacional de Educación Sexual (CENesex).

El contrapunto lo pone la violencia machista, una problemática que tradicionalmente ha sido vista como perteneciente al ámbito privado familiar y, por tanto, no sujeta a la intervención estatal. Actualmente, resulta especialmente preocupante la falta de un protocolo de actuación frente a este problema y la ausencia de datos y estadísticas sobre su repercusión en la Isla.

${ }^{29}$ Art. cit. Véase, además, Macías Amores, op. cit., pp. 257-258, y Macías Amores, "Revolución Cubana: Mujer, Género y Sociedad Civil", Viento Sur, 2 de marzo de 2011 , p. 8.

${ }^{30}$ Vasallo Barrueta, op. cit., pp. 74-65.

${ }^{31}$ G. Alfonso González, "Desafíos del feminismo socialista en la Cuba actual”, América Latina en Movimiento. Feminismo popular para cambiar el mundo, núm. 489, 2013, pp. 20-22.

32 Movimientos..., pp. 99-100. 
En Cuba, el feminicidio no está incluido en la legislación penal y tales casos se valoran como asesinatos sujetos a la agravante por parentesco con la víctima. Ese tratamiento no deja claras las motivaciones de género presentes en el feminicidio. ${ }^{33}$ Tampoco hay estadísticas oficiales que permitan visibilizar la violencia machista y definir estrategias para erradicarlo. A pesar de que las investigaciones realizadas confirman la existencia de este problema en Cuba, reflejando además la vulnerabilidad legal, social y económica de las víctimas, sigue sin haber estadísticas públicas sobre esta cuestión. ${ }^{34}$ La experta cubana en violencia de género, Clotilde Proveyer, insiste en la necesidad de recoger datos empíricos sobre la prevalencia de esta problemática en el país, aplicar teorías y metodologías acordes para actualizar la legislación al respecto y promover políticas y programas de atención y prevención. ${ }^{35}$

Simultáneamente, el periodo de reformas sociopolíticas abierto con el gobierno de Raúl Castro ha propiciado nuevos espacios de crítica. Entre otros, se ha intensificado el debate sobre el feminismo, la inclusión de la perspectiva de género y sobre la desconexión entre las reflexiones que en este sentido se dan en el ámbito académico y las políticas públicas impulsadas desde las instituciones. Desde el Centro de Investigaciones Psicológicas y Sociológicas (CIPS) se ha reconocido que "las teorías feministas, los estudios de género y masculinidades ganan espacio” en el ámbito académico. Pero se reclaman más investigaciones cuantitativas, por ejemplo respecto a la violencia de género y una "mayor atención de las instituciones a los resultados de investigaciones sociales". ${ }^{36}$

${ }^{33}$ R. Campoalegre Septien, "Feminicidio: lo esencial no puede ser invisible", SEMLAC, 22 de mayo de 2016.

${ }^{34}$ Cf. los siguientes trabajos de S. Mas: "Violencia de género. La ley no es suficiente", Rebelión, 8 de diciembre de 2011; "Violencia de género. En busca de respuestas más efectivas", Rebelión, 27 de marzo de 2012; y "Urge protocolo de actuación frente a violencia de género", SEMLAC, 30 de marzo de 2016.

35 "Violencia de género. Aproximación desde la realidad cubana", Revista Sexología y Sociedad, vol. 20, núm. 1, 2014, pp. 3-17.

${ }^{36}$ L. Gordillo Piña, "Cambios imponen desafíos a las ciencias sociales", SEMLAC, 19 de octubre de 2015. 
En el encuentro sobre feminismo organizado en marzo de 2015 por la sección cubana de la Marcha Mundial de las Mujeres, el Instituto de Filosofía de la Universidad de La Habana y la FMC, se exponía precisamente que "incorporar el enfoque feminista a los procesos de desarrollo social en Cuba es una necesidad en el contexto de transformaciones que vive el país caribeño de gobierno socialista”. Asimismo, se reflexionó sobre la depauperación del feminismo en la academia y otros ámbitos de la sociedad cubana y el rechazo a este término. Según la periodista Helen Hernández Hormilla, este rechazo esconde "la misoginia vigente en buena parte de los espacios de poder". En el encuentro aludido, se reclamó la necesidad de tener en cuenta las investigaciones y reflexiones al respecto llevadas a cabo desde la comunidad científica a la hora de diseñar políticas públicas y actualizar la legislación vigente. ${ }^{37}$

En este sentido, cabe mencionar la apertura del Espacio Feminista "Berta Cáceres" impulsado desde el Grupo América Latina, Filosofía Social y Axiología (GALFISA), en cuya inauguración, en mayo de 2016, Alfonso González enfatizaba la importancia de articular el debate desde "el respeto a la diversidad de nuestras identidades, la solidaridad de todas las mujeres protagonistas del cambio anticapitalista en la nueva coyuntura histórica, regional y global". ${ }^{38}$

La falta de reconocimiento del feminismo también ha resultado en una desconexión con el movimiento feminista latinoamericano, señalándose como reto del movimiento de mujeres cubano la articulación de sus luchas con las de los grupos de mujeres y feministas en el resto del continente. ${ }^{39}$ Desde Galfisa también se está trabajando la participación en las redes feministas latinoamericanas, según lo comprueba la celebración de encuentros como el de marzo de 2015, al que se aludió líneas arriba.

37 "Feminismo, un debate necesario para Cuba", sEMLAC, 16 de marzo de 2015.

${ }^{38}$ L. Gordillo Piña, "Feministas cubanas estrenan nuevo espacio de debate", SEMLAC, 9 de mayo de 2016.

${ }^{39}$ Alfonso González, art. cit., pp. 20-22. 


\section{Representación}

La Revolución cubana puede considerarse un proceso revolucionario clásico en el que se implantó un sistema socialista de partido único que ha permanecido hasta hoy. El Comité Central del Partido Comunista de Cuba (PCC) cuenta con 142 miembros, con la participación de representantes de las diferentes organizaciones de masas. Entre estos últimos encontramos a Teresa María Amarillee Boué, Secretaria General de la Dirección Nacional de la FMC, que también figura entre los 17 miembros del Buró Político. Los estatutos del PCC plantean la constante vinculación con la sociedad civil cubana por medio de la FMC y otras organizaciones sociales. ${ }^{40}$

En general, la ocupación de posiciones de poder ha sufrido un aumento sostenido desde los albores del proceso revolucionario. ${ }^{41}$ Las mujeres constituyen el $43 \%$ en la Asamblea Nacional, y en el VI Congreso del PCC, en abril de 2011, su presencia en el Comité Central pasó del 17 al 45\%, si bien siguen representando alrededor de un tercio de los altos dirigentes. Hay 4 mujeres, en fin, entre los 17 miembros del Buró Político.

Según el Informe Central al VII Congreso del PCC de abril de 2016 representan el 38\% de los cargos en los órganos del Estado, organismos del gobierno, entidades nacionales, Consejos de la Administración y Organizaciones Superiores de Dirección Empresarial. $^{42}$

En cualquier caso, según la socióloga feminista del Centro de Estudios de la Economía Cubana de la Universidad de La Habana, Dayma Echevarría, en Cuba "el socialismo es patriarcal en muchos aspectos", de modo tal que mayor presencia en las instancias legislativas y políticas no ha significado un cambio cualitativo en el ejercicio del poder. ${ }^{43}$

40 Estatutos del PCC.

${ }^{41}$ Macías Amores, art. cit., pp. 17-19.

42 Informe Central al VII Congreso del PCC, La Habana, 16 de abril de 2016.

43 "América Latina: feminismos en el camino de la emancipación”, SEMLAC, 20 de enero de 2015. 


\section{Redistribución}

La incorporación de las mujeres al ámbito productivo ha visto un aumento sostenido a lo largo del proceso revolucionario. Si en 1953 constituían el 12\% de la fuerza laboral, en 2009 representaban ya el $46 \%$ del sector estatal civil, aunque con mayor presencia en cargos administrativos y técnicos que como operarias y dirigentes. En el ámbito del trabajo por cuenta propia continúan siendo minoría, un $26 \%$ actualmente, y predominan en trabajos relacionados con sus roles de género. Son más del $60 \%$ de las personas graduadas universitarias. Y, según datos aportados por el Centro de Estudios de la Mujer de la FMC y la Oficina Nacional de Estadísticas e Información (ONEI), hay igualdad de salarios entre hombres y mujeres por trabajos de igual valor y preparación. ${ }^{44}$

Sin embargo, se mantiene, por tanto, una división sexual del trabajo tanto en la función pública como en el trabajo por cuenta propia, que suponen una peor remuneración para ellas. Se asigna a las mujeres trabajos desvalorizados en el ámbito del cuidado, el sector servicios y administración, mientras los hombres siguen siendo mayoría en las especialidades técnicas y científicas, que suponen mayores ingresos. Esta división sexual del trabajo es evidente en el ámbito reproductivo, donde no se ha dado una redistribución. A pesar de las disposiciones establecidas en el Código de Familia de 1975 -relativas a la igualdad de derechos y deberes de hombres y mujeres en el ámbito del hogar-, la incorporación a tareas productivas ha supuesto duplicar la carga de trabajo de las mujeres, ya que han continuado siendo responsables de las labores domésticas.

En Cuba hay más de 2766000 mujeres económicamente activas que son el $66 \%$ de la fuerza profesional y técnica, según el último Censo de Población y Viviendas, realizado en 2012 por la ONEI. Sin embargo, este informe también muestra más de 1698000 cubanas dedicadas al trabajo doméstico, es decir el $92 \%$ de las personas dedicadas a estos quehaceres en el país. Resultados semejantes se obtuvieron de la única Encuesta del Tiempo realizada en 2002:

${ }^{44}$ I. Moya, art. cit.; N. Vasallo, op. cit., p. 198. 
las cubanas dedican el $71 \%$ de sus horas laborales al trabajo doméstico no remunerado. ${ }^{45}$

La división sexual del trabajo expresa, según la economista Teresa Lara, la violencia económica que hay para con las mujeres en Cuba, también relacionada con la asignación de un poder monetario a los hombres. Este poder se refleja en el ejercicio de control sobre las mujeres y supone uno de los elementos clave de la violencia de género. ${ }^{46}$ Esta violencia económica se agudiza en periodos de crisis. Las mujeres sufrieron especialmente la deteriorada situación económica del Periodo Especial, con un aumento del desempleo femenino y una carga de trabajo extra en tareas domésticas y de cuidados que antes correspondían a personas profesionales contratadas o al Estado. ${ }^{47}$ En la actualidad, tal y como lo denuncian las economistas Dalia Virgilí, Dayma Echevarría y Teresa Lara, la falta de una perspectiva de género en las medidas económicas introducidas desde 2008, relacionadas con las reformas recogidas en los Lineamientos de Política Económica y Social de 2011, redunda en la desigualdad de oportunidades para las mujeres. ${ }^{48}$

La reducción de plantillas en el sector estatal iniciada en 2009 recortó 596500 empleos hasta 2014 fundamentalmente en el sector terciario, donde se concentra la mano de obra femenina. Muchas de las mujeres que se quedaron sin empleo se han incorporado al sector privado de manera informal y, por tanto, precarizada.

Respecto a la promoción del cuentapropismo se abren oportunidades para las mujeres, con salarios entre 3 y 10 veces mayores que los estatales. La inclusión en la seguridad social de mujeres que antes trabajaban en la economía sumergida también supone un avance. Y en el caso de la jubilación de trabajadoras cuentapropistas de edad avanzada que no habían pertenecido al mundo laboral regulado, se les han otorgado beneficios a la hora de recibir las pensiones, sin necesidad de un recorrido laboral tan largo como

${ }^{45}$ H. Hernández Hormilla, "Más vulnerables ante la reforma económica", en Cubanas en el vórtice del empleo, La Habana, SEMLAC, 2015, pp. 8-11.

${ }^{46} \mathrm{Id}$.

${ }^{47}$ I. Moya, art. cit.; Macías Amores, art. cit., pp. 13-17; Molyneux, Movimientos..., pp. 142-147.

${ }^{48}$ H. Hernández Hormilla, art. cit., pp. 8-11. 
en otros supuestos. Sin embargo, la mayoría de las actividades impulsadas siguen siendo tradicionalmente masculinas y en muchos casos las mujeres no cuentan con el capital inicial necesario para comenzar un negocio, de nuevo concentrado en las manos de los varones. ${ }^{49}$

Tampoco se prevén políticas de conciliación o redistribución de las tareas domésticas, ni servicios de apoyo a la vida doméstica, que tengan en cuenta la situación de las mujeres, tradicionalmente responsables del trabajo reproductivo. Los recortes del gasto público conllevaron la reducción de escuelas internas en ámbitos rurales, el cierre de comedores obreros y el recorte del presupuesto de asistencia social de 656.2 millones de dólares, en 2008, a 262.9, en 2013, según la ONEI. ${ }^{50}$

\section{Participación de los MOViMientos de MUJERES EN LOS PROCESOS CONSTITUYENTES DE BOLIVIA Y ECUADOR}

La llegada al gobierno del Movimiento al Socialismo (MAs), en Bolivia (2006), y de Alianza PAís, en Ecuador (2007), se enmarcó en el ciclo de contestación social que tuvo lugar en América Latina desde finales de los años ochenta. Las movilizaciones contribuyeron al triunfo sucesivo en la primera década del 2000 de gobiernos de corte progresista vinculados a los movimientos populares. ${ }^{51}$ Desde las bases sociales y las organizaciones políticas resultantes se expresaba un fuerte cuestionamiento de las políticas neoliberales causantes de la crisis económica en la "década perdida” de los años ochenta. Tanto el equipo de Evo Morales, en Bolivia, como el de Rafael Correa, en Ecuador, llegaron al gobierno

${ }^{49}$ D. Cobo, "Y el «cuentapropismo», ¿liberó a las mujeres?", Revista Pikara, 26 de febrero de 2014.

${ }^{50}$ H. Hernández Hormilla, art. cit., pp. 8-11.

${ }^{51}$ B. Bringel y M. Almudena Cabezas, "Geopolítica de los movimientos sociales latinoamericanos: espacialidades, ciclos de contestación y horizonte de posibilidades", en Anuario de la integración latinoamericana y caribeña 2011, Nueva Orleans, University Press of the South-Ediciones de la Noche, 2014, pp. 323-342. 
con la voluntad de dar un giro a estas políticas, al ser un mecanismo clave en ambos procesos la reforma constituyente.

En la elaboración de las nuevas constituciones de Bolivia (2009) y Ecuador (2008) participaron mediante sendas Asambleas Nacionales Constituyentes los movimientos sociales que protagonizaron la contestación en ambos países. ${ }^{52}$ Junto con movimientos indígenas, campesinos u Organizaciones no Gubernamentales (ONG) de origen diverso, las organizaciones de mujeres tuvieron un papel notable en las movilizaciones y los procesos constituyentes.

La articulación de estos procesos fue, por tanto, más cercana a la visión de los movimientos sociales contemporáneos sobre la participación directa de la ciudadanía que a la organización de la izquierda tradicional en torno a partidos de vanguardia y liderazgos más verticales, en la que se basó el proceso revolucionario cubano. No se apuesta por la toma de poder para transformar a la sociedad, sino que buscan un proceso de "participación, apropiación y empoderamiento" en el que se promueve el protagonismo de cada uno de los actores sociales en la elaboración de un proyecto alternativo. ${ }^{53}$

En estas circunstancias, las organizaciones de mujeres que han participado en las constituyentes son movimientos feministas autónomos o forman parte de un tejido asociativo que ha seguido una trayectoria similar a la corriente feminista tradicional y a la popular (en esta última, cabe destacar particularmente la corriente comunitaria en el caso de Bolivia). Estos movimientos han estado alineados, por tanto, con la evolución internacional del feminismo. La incorporación de sus demandas al ámbito institucional previo a las constituyentes tuvo que ver con el impulso de la política de género desde la Organización de Naciones Unidas (ONU) a partir de la década de los setenta. Posteriormente se han mantenido vinculados al activismo feminista latinoamericano e internacional, que

52 S. Martí i Puig y C. Bastidas, “¿Ha Cambiado la protesta? La coyuntura actual de movilizaciones en Bolivia y Ecuador”, Iconos. Revista de Ciencias Sociales, núm. 44, 2012, p. 20.

${ }^{53}$ I. Rauber, "Gobiernos populares en América Latina y el Caribe: ¿revoluciones o neorreformismo?”, Pasos, núm. 137, 2008, pp. 6-13. 
entre los años ochenta y la primera década del presente siglo tuvieron un auge por el Movimiento Antiglobalización. ${ }^{54}$

\section{Reconocimiento}

La participación de mujeres y grupos feministas en las constituyentes ha supuesto en ambos estados la inclusión de la teoría y la práctica feminista a nivel constitucional. La incorporación en ambas constituciones de la propuesta del Sumak Kawsay o Buen Vivir, asociada a la cosmovisión indígena, supone una orientación política hacia el desarrollo de una economía del cuidado, basada en principios de reciprocidad, cooperación y solidaridad. Esta visión se nutre no poco de las reflexiones provenientes del feminismo. ${ }^{55}$ Este reconocimiento también ha visibilizado a las mujeres indígenas como sujetos políticos y se han dado aportes relevantes en el ámbito teórico y en cuanto a la articulación de movimientos de mujeres indígenas.

En Bolivia, la institucionalidad pública de género recae en el Viceministerio de Igualdad de Oportunidades que depende del Ministerio de Justicia. Según el último Informe para el Comité para la Eliminación de todas las formas de Discriminación contra la Mujer (CEDAw), ha visto reducida su capacidad para la toma de decisiones, la elaboración de políticas públicas y para influir en el resto de instancias gubernamentales. Cuenta con escasos recursos humanos y un reducido presupuesto. Y el Plan Nacional para la Igualdad de Oportunidades "Mujeres construyendo la nueva Bolivia para vivir bien” no ha llegado a ser implementado. Las orga-

${ }^{54}$ Perea Ozerin, art. cit., pp. 7-15.

${ }^{55}$ M. León, "Después del «desarrollo»: el «buen vivir» y las perspectivas feministas para otro modelo en América Latina”, Umbrales (Género y desafíos post-neoliberales), núm. 18, 2008, pp. 35-38; I. León, "Ecuador: la tierra, el Sumak Kawsay y las mujeres”, en Sumak Kawsay/Buen Vivir y cambios civilizatorios, Quito: FEDAEPs, $2^{\text {a }}$ ed., 2010, pp. 143-153; E. Agreda, "Del proceso Constituyente al Vivir Bien desde la mirada de las mujeres", en Mujeres en diálogo: avanzando hacia la despatriarcalización, La Paz, Coordinadora de la Mujer, 2012, pp. 68-70. 
nizaciones de mujeres reclaman la creación de un Ministerio de la Mujer. ${ }^{56}$

Se creó el Comité Nacional contra el Racismo y toda forma de Discriminación (2010) y se ha añadido la Unidad de Despatriarcalización al Viceministerio de Descolonización liderado por Félix Cárdenas y dependiente del Ministerio de Cultura y Turismo. La creación de este órgano está directamente relacionada con las reivindicaciones de la Asamblea Feminista de Bolivia, que subraya la necesidad de aprovechar el proceso de descolonización iniciado con el gobierno de Evo Morales para llevar a cabo un proceso de despatriarcalización. ${ }^{57}$

A pesar de los avances legislativos realizados respecto a la igualdad de género, en el Informe Sombra de las Mujeres Indígenas de Bolivia se denuncia su exclusión en la política de género en el país. Se afirma que estos avances no tienen mayor impacto en sus ámbitos ya que no se adecuan a sus realidades. ${ }^{58}$

En el caso de Ecuador, tanto el presidente Correa como feministas cercanas al gobierno, como Magdalena León de la Red de Mujeres Transformando la Economía (REMTE), han teorizado el Buen Vivir, con aportaciones teóricas importantes desde una perspectiva feminista. Sin embargo, Correa mantuvo una actitud de confrontación con el feminismo y movimientos feministas autónomos que contrasta con este reconocimiento inicial. Además, el Informe Sombra para 2014 señala que "la reproducción de la violencia

${ }^{56}$ Informe Sombra Bolivia 2014: Coalición de Organizaciones de Derechos Humanos de las Mujeres de la Sociedad Civil, "Contribuciones de la Coalición de Organizaciones de Derechos Humanos de las Mujeres de la Sociedad Civil para la elaboración de la Lista de Cuestiones sobre el quinto y sexto informe periódico estatal, para su adopción por el CEDAw", Bolivia, octubre de 2014, p. 8. Esta coalición está constituida por 135 organizaciones e instituciones de mujeres. El presente informe constituye una complementación y una actualización del Informe de Sociedad Civil al CEDAw, presentado el 20 de noviembre de 2013.

${ }^{57}$ F. Sánchez Jaramillo, "Entrevista a Julieta Paredes”, Rebelión, 19 de diciembre de 2014.

${ }^{58}$ Informe Sombra de las Mujeres de Naciones y Pueblos Indígenas de Bolivia, elaborado por la Confederación Nacional de Mujeres Indígenas de Bolivia, el Consejo Nacional de Ayllus y Markas del Qullasuyu y la Confederación Nacional de Pueblos Indígenas de Bolivia, julio de 2015, pp. 3-6. 
simbólica y de los imaginarios patriarcales, de relaciones de género alrededor de la figura presidencial, se da como parte del lenguaje y las relaciones de poder". A pesar de la presencia de mujeres en cargos de decisión en el gobierno "prima una visión de la figura femenina subordinada, lo que sin duda contribuye a la naturalización de las violencias de género". ${ }^{59}$

Los movimientos de mujeres ecuatorianos también denuncian el debilitamiento de la institucionalidad referente a la igualdad de género con la reestructuración institucional entre 2009 y 2014. El Consejo Nacional de las Mujeres (CONAMU) fue finalmente desmantelado. Se creó la Comisión de Transición hacia el Consejo de Igualdad (CDT), que, en 2009, al igual que todos los Consejos de Igualdad, perdió su capacidad rectora de políticas públicas. La eliminación del conAMU, que tenía carácter de órgano rector de la formulación y promoción de políticas de género, y estaba anclado directamente a la Presidencia, dificulta la formulación y ejecución de estas políticas, así como la implementación de una estrategia de transversalidad de género en políticas públicas.

Además, se critica la falta de reconocimiento de los actores sociales, incluidos los movimientos de mujeres autónomos y la cooptación de los mismos. ${ }^{60}$ Las críticas desde organizaciones sociales a los mecanismos de participación social previstos en la Constitución de 2008 y la Ley de Participación Ciudadana se recogen en la postura del Colectivo Coordinador alames Ecuador, que ha descrito la concepción gubernamental de participación social

${ }^{59}$ Informe Sombra al Comité de la CEDAw, elaborado por la Coalición Nacional de Mujeres para la Elaboración del Informe Sombra de la CEDAw, Quito (Ecuador), noviembre de 2014, p. 6. En la elaboración de este informe participaron siete organizaciones nacionales de mujeres (Plataforma Nacional por los Derechos de las Mujeres, Movimiento de Mujeres de Sectores Populares Luna creciente, Coordinadora Política de Mujeres, Red de Mujeres Políticas del Ecuador, Frente Ecuatoriano de Derechos Sexuales y Reproductivos, Confederación Ecuatoriana de Mujeres por el Cambio y Colectivo Nosotras), cinco provinciales (Cabildo por las Mujeres del Cantón Cuenca, Movimiento de Mujeres de Manabí, Federación de Mujeres de Sucumbíos, Mujeres de Frente, Consejo de Mujeres y Negras-San Lorenzo), y dos ongs (ACDemocracia y Surkuna).

${ }^{60}$ Ibid., p. 27. 
como "un espacio subordinado a la direccionalidad del Gobierno para convertirse en validador de las políticas estatales". ${ }^{61}$

Respecto a la agenda feminista, los movimientos de mujeres bolivianos alcanzaron importantes logros en lo que se refiere a la elaboración de la Constitución. Se incorporó un lenguaje no sexista y se incluyó casi una treintena de artículos que garantiza los derechos humanos de las mujeres. ${ }^{62}$ El Informe para la CEDAw de 2014 subraya especialmente los avances en el marco jurídico y normativo para la protección de los derechos humanos de las mujeres. ${ }^{63}$

En cuanto al proceso ecuatoriano, las organizaciones de mujeres participantes buscaban integrar los puntos recogidos en la Agenda de las Mujeres para la Nueva Constitución. Sus "reivindicaciones irrenunciables" fueron establecidas en la pre-Constituyente de Mujeres del Ecuador en junio de 2007, que fundamentalmente consiste en: establecer un Estado laico que incluya el derecho a la libertad de conciencia y de adoptar decisiones; derecho a la igualdad real o material; derecho de decidir sobre el cuerpo, salud, vida sexual y reproducción; paridad en las instituciones; justicia de género, respecto a la violencia machista; erradicación del sexismo, machismo, androcentrismo y prácticas discriminatorias; conciliación, en fin, de la labor productiva y reproductiva. ${ }^{64}$ Lo que se recogió en ambas constituciones, con todo, contrasta con las políticas impulsadas respecto a derechos sexuales y reproductivos de las mujeres.

A pesar de que los abortos clandestinos en Bolivia continúan provocando una alta tasa de mortalidad materna, en un reciente fallo del Tribunal Constitucional se rechazaba, por parte de la diputada del mas Patricia Mancilla, la petición de inconstitucionalidad de trece artículos del Código Penal que penalizan la interrupción

${ }^{61}$ Ibid., p. 42.

${ }^{62}$ Véanse, por ejemplo, artículos 8, 11, 14, 15, 26, 66, 338, 395 o 402 de la Constitución Política del Estado de Bolivia, 7 de febrero de 2009.

${ }^{63}$ Informe Sombra Bolivia 2014, p. 3.

${ }^{64}$ Constitución de la República del Ecuador. Véase también P. Palacios Jaramillo, "Los derechos de las mujeres en la nueva Constitución", Institute for Research and Debate on Governance, marzo de 2008. 
del embarazo, a la luz de las disposiciones recogidas al respecto en la nueva Constitución citadas anteriormente. Únicamente se recoge su despenalización en caso de violación, pero aun así las víctimas se enfrentan a posibles "objeciones de conciencia" del personal sanitario. ${ }^{65}$

En Ecuador, el aborto es ilegal, salvo en casos en los que el embarazo ponga en peligro la vida o la salud de la mujer, mientras que en otras situaciones la ley castiga con prisión tanto a las mujeres como a los médicos que incurran en esta práctica. El Frente Ecuatoriano de Defensa de los Derechos Sexuales y Derechos Reproductivos (DS-DR) intervino activamente en la protección del aborto terapéutico (2007) y en el proceso de elaboración de la nueva constitución (2008), defendiendo el derecho de decidir en aspectos relacionados con la sexualidad y reproducción, todo lo cual se reconoce en la Constitución.

Sin embargo, se ha impuesto la actitud del presidente Rafael Correa, invocando su conciencia y educación cristiana. ${ }^{66}$ En octubre de 2013, cuando en el marco de la reforma del Código Penal asambleístas de AP presentaron una propuesta para despenalizar el aborto en caso de violación, Correa amenazó con dimitir si se aprobaba esta medida y las tres asambleístas fueron sancionadas. ${ }^{67}$ Fue especialmente contestatario con el Frente de Defensa de los DS-DR, con quienes rechazó reunirse. Y ensalzó los valores de la familia ecuatoriana frente a la "absurda" y "peligrosísima" ideología de género. ${ }^{68}$ Esta posición conservadora se reflejó en la sustitución de la ENIPLA (Estrategia Nacional Intersectorial Planificación Familiar y Prevención del Embarazo en Adolescentes), lanzada en

65 J. Ybarnegaray Ortiz, "Un fallo engorroso y vocinglero", América Latina en Movimiento, 17 de febrero de 2014.

${ }^{66}$ P. Palacios Jaramillo, art. cit. Véase asimismo la "Intervención del presidente de la República, Rafael Correa, en la ceremonia de inauguración de la Asamblea Nacional Constituyente”, Montecristi, 30 de septiembre de 2007, pp. 24-25.

67 "Rafael Correa amenaza con dimitir si se aprueba la despenalización del aborto", El Mundo, 11 de octubre de 2013.

68 "Rafael Correa rechaza la «absurda» y «peligrosísima» ideología de género", Infobae, 3 de enero de 2014. 
2011, por el Plan Familia, denunciado como un importante retroceso en derechos de las mujeres. ${ }^{69}$

Respecto a la violencia machista, en Bolivia se contempla de forma transversal en la Ley Integral para Garantizar una Vida Libre de Violencia de 2013. Según datos de la onu Mujeres de noviembre de 2013, Bolivia figuraba como el país latinoamericano donde mayor porcentaje de mujeres afirma haber sufrido este tipo de violencia (52\%), mientras que Ecuador se encontraba en cuarto lugar $(31 \%) .^{70}$ Según los últimos datos oficiales, 9 de cada 10 mujeres en Bolivia son víctimas de violencia. A la luz de estos datos, Julieta Montaño, de la Oficina Jurídica para la Mujer en Bolivia, critica la falta de voluntad política y que no se destinen los recursos suficientes para que esta ley se aplique de forma efectiva. ${ }^{71}$ Las mujeres indígenas denuncian que los mecanismos de protección existentes sobre violencia de género no se adecuan a sus realidades. ${ }^{72}$

En Ecuador, al igual que en la Constitución Política del Estado de 1998, en la de 2008 se reconoció el derecho de las mujeres y niñas a una vida libre de violencias, se estableció la erradicación de la violencia de género como política de Estado y se presentó el Plan Nacional para la Erradicación de la Violencia de Género. ${ }^{73}$ El "feminicidio" se incluyó en la Reforma del Código Orgánico Integral Penal (COIP) de 2014 y se crearon los juzgados especializados contra la violencia a la mujer y la familia. Sin embargo, los movimientos de mujeres denuncian la ausencia de una política de prevención de violencia de género y la persistencia en los órganos responsables de estereotipos contra las mujeres y víctimas de violencia. No se dio

${ }^{69}$ Plan V, "Plan Familia Ecuador o un retroceso de cien años", 14 de marzo de 2015 .

70 "Violencia contra la mujer cobra este año 1800 vidas en América Latina", Cubadebate, 25 de noviembre de 2013.

${ }^{71}$ F. Goldsman, "Entrevista a Julieta Montaño", Revista Pikara, 2 de junio de 2015.

${ }^{72}$ Informe Sombra de las Mujeres de Naciones y Pueblos Indígenas de Bolivia..., pp. 5-8.

${ }^{73}$ Consúltese la siguiente dirección en línea: http:/ /www.justicia.gob.ec/wpcontent/uploads/2014/08/plan_erradicacionviolencia_ecuador.pdf. 
una implementación integral y ordenada del Plan, las campañas no llegaron a las zonas rurales, en muchos de estos lugares no hay las Unidades de Violencia contra la Mujer y la Familia (UvmF), el nuevo coIP no protege a estas víctimas de forma oportuna, no hay medidas de protección inmediata y se culpabiliza a las víctimas. Las mujeres indígenas también denuncian el incumplimiento de los artículos constitucionales que garantizan su protección bajo la justicia ordinaria u originaria. ${ }^{74}$

\section{Representación}

En Bolivia, la participación de las mujeres en la Asamblea Constituyente de 2006 fue inédita en el país, pues alcanzó el $34.51 \%$. También destacó la elección de Silvia Lazarte, dirigente de la Federación de Mujeres Bartolina Sisa, como presidente de este órgano. ${ }^{75}$ Actualmente cuenta con el $54 \%$ de mujeres en la Asamblea Legislativa Plurinacional, electas en los últimos comicios electorales en octubre de 2014. Aunque se ha denunciado la integración por parte del mas de mujeres en cargos de suplentes en el Parlamento para cumplir con las cuotas, de forma que el porcentaje de titulares de esta bancada sería menor al $14 \%$ de los escaños obtenidos en la primera legislatura. ${ }^{76}$ Desde organizaciones de mujeres indígenas se han hecho críticas similares. Denuncian que la paridad y alternancia recogidas en la Constitución Política de 2009 y en la Ley de Régimen Electoral presenta debilidades en lo que se refiere a las mujeres indígenas. Esta representación se relega a la figura de suplente de un hombre. ${ }^{77}$

En Ecuador, se han dado pasos en lo que toca a la inclusión de criterios de paridad a la hora de formar gobierno y ya el pri-

${ }^{74}$ Informe Sombra Ecuador 2014, pp. 6-19.

${ }^{75}$ E. Agreda, art. cit., pp. 63-64.

${ }^{76}$ M. Cabezas Fernández, "De orgánicas e invitadas: una mirada a la participación de las mujeres en la bancada del Movimiento al Socialismo (2006-2008)”, Umbrales (Género y desafíos post-neoliberales), núm. 18, 2008, p. 243.

77 Informe Sombra de las Mujeres de Naciones y Pueblos Indígenas de Bolivia, pp. 5 y 8. 
mer gabinete formado por Rafael Correa constaba de la mitad de mujeres. El principio de paridad está incluido en la Constitución ecuatoriana. ${ }^{78}$ Se logró un gobierno con presencia creciente de mujeres. En las elecciones de 2009, las primeras realizadas tras la constituyente, la participación de las mujeres fue del $40 \%$ en asambleístas nacionales, del $31.1 \%$ en provinciales y del $33.3 \%$ en asambleístas del exterior. En las elecciones de 2013, esos porcentajes ascendieron al $46.7 \%, 37.1 \%$ y $50 \%$, respectivamente. El Consejo Nacional Electoral también creó una Comisión de Inclusión, encargada de producir información con el propósito de "adoptar las medidas necesarias en aras a garantizar la incorporación en igualdad de derechos a sectores tradicionalmente discriminados y marginalizados, y con enfoque de género".79

Sin embargo, según el último Informe Sombra, a pesar del incremento en la representación política de las mujeres, el fuerte posicionamiento del presidente Correa contra la política de género disuadía a las mujeres en cargos de decisión de trabajar por la igualdad de género y actuar en defensa de los intereses de las mujeres. ${ }^{80}$ En este mismo documento se denunciaba la violencia para con las mujeres que participan en política, especialmente grave en los municipios. El 25 de noviembre de 2012, la Asamblea de Mujeres Municipalistas del Ecuador (Amume) presentó en la Asamblea Nacional el proyecto de Ley contra la Violencia Política de Género, que quedó archivado. ${ }^{81}$ En Bolivia, esta problemática llevó a la aprobación, en 2012, de la Ley contra el Acoso y la Violencia Política hacia las Mujeres, que introduce en el Código Penal las figuras delictivas de acoso político y violencia política contra las mujeres. ${ }^{82}$

${ }^{78}$ P. Palacios Jaramillo, art. cit.

${ }^{79}$ M. Aguiñaga, "La equidad de género en la cultura política”, Asamblea Nacional República de Ecuador, 26 de junio de 2013.

${ }^{80}$ Informe Sombra Ecuador 2014, p. 41.

${ }^{81}$ Ibid., p. 41.

${ }^{82}$ Informe Sombra Bolivia 2014, p. 3. 


\section{Redistribución}

En Bolivia, durante el periodo de gobierno del MAs, se ha logrado reducir la pobreza del $56 \%$ al $39 \%$ y entre 2005 y 2013, según datos oficiales, se redujo la tasa de desempleo del $8.1 \%$ al $3.2 \% .{ }^{83}$ Estos indicadores suelen reflejar una mejora de la calidad de vida de los sectores en desigualdad, como el de las mujeres. Se adoptaron medidas en materia laboral, como el incremento del salario mínimo, reconocimiento de derechos laborales para las mujeres embarazadas y en periodos de lactancia y políticas activas de empleo concebidas para mujeres jóvenes. Pero en 2011, la tasa de ocupación de las mujeres era del $48.5 \%$, mientras que la de los hombres llegó al 69.5\%. También se mantuvo la brecha en la tasa de desempleo y la predominancia de las mujeres en el sector informal, pues el $68.62 \%$ del empleo correspondía a las mujeres, mientras que el $55.79 \%$ a los hombres. Persiste una división sexual del trabajo con las mujeres en el ámbito de servicios y los hombres en sectores productivos y extractivos. Y la brecha salarial apenas se redujo entre 2009 y 2011, del 62\%, que representaba el ingreso promedio de las mujeres respecto al de los hombres, al $60 \%$.

En el informe rendido a la CEDAw, se reconoce la Ley sobre el Trabajo Decente para las Trabajadoras y Trabajadores Domésticos de 2012, que regula las condiciones laborales en este sector, mayoritariamente formado por mujeres, y que recoge también el respeto a la igualdad de género y la protección de las trabajadoras migrantes. Aunque también se señala que quedan pendientes políticas públicas para el trabajo no remunerado y su inclusión en las cuentas públicas. $^{84}$

Las transferencias condicionadas directas, como los bonos, benefician fundamentalmente a las mujeres. Pero el $61 \%$ de los bonos está dirigido a mujeres, reconocidas como beneficiarias por su con-

83 "Gobierno de Evo Morales mejoró calidad de vida de bolivianos", Telesur, 2 de agosto de 2016. En el caso de las mujeres indígenas se denuncia la falta de datos desagregados sobre su situación de empleo (Informe Sombra de las Mujeres de Naciones y Pueblos Indígenas de Bolivia, p. 9).

${ }^{84}$ Informe Sombra Bolivia 2014, pp. 15-19. 
dición de madres. ${ }^{85}$ Como ocurre en Ecuador, este mecanismo refuerza el rol de género de las mujeres como responsables del cuidado.

En Ecuador, las dos legislaturas bajo la presidencia de Correa también destacaron por los logros económicos. Desde 2007, se redujo la pobreza del $36.7 \%$ al $23.3 \%$ en 2015 , con un descenso mayor en zonas rurales: del $61.3 \%$ al $35.3 \%$. Además, se sitúa entre los países latinoamericanos que más redujo la desigualdad entre 2007 y 2013; el coeficiente de Gini bajó 6 puntos (del 0.55 al 0.49), mientras que en el conjunto de Latinoamérica bajó 2 puntos (del 0.52 al 0.50$)$.

En educación aumentó la tasa de matriculación en educación básica y es el país que más invierte en educación superior (2\% de su PIв). ${ }^{86}$ Aunque si consideramos la tasa de analfabetismo, si bien se ha reducido en general desde 2001, persiste la brecha entre mujeres y hombres $(7.7 \%$ frente a $5.8 \%)$, especialmente preocupante en el caso de las mujeres indígenas, que registran una tasa del $26.8 \% .87$

Entre 2007 y 2009, se incrementó la incorporación de las mujeres al ámbito productivo de forma notable, a causa de las mejoras salariales, los programas de emprendimiento productivo para las mujeres y la inclusión de las trabajadoras domésticas remuneradas en la Seguridad Social. Sin embargo, el desempleo sigue siendo mayor entre las mujeres. Según la Encuesta Nacional de Empleo y Desempleo Urbano, la tasa de desempleo nacional a junio de 2014 fue de $5.1 \%$ entre hombres y $6.6 \%$ entre mujeres. Las mujeres siguen siendo las más presentes en el sector informal, de lo cual se desprenden sus malas condiciones laborales. Si miramos la tasa de ocupación plena: $57.4 \%$ de la población económicamente activa masculina está ocupada, mientras que el $46.1 \%$ de la femenina entra en esa categoría. ${ }^{88}$

El mantenimiento del modelo extractivista, contra lo estipulado en el Plan Nacional del Buen Vivir 2013-2017, con megaproyectos mineros y petroleros en zonas que habitan pueblos indígenas y

85 Ibid., p. 11.

86 “¿Cuánto ha cambiado Ecuador con la Revolución Ciudadana?”, Telesur, 24 de mayo de 2016.

${ }^{87}$ Informe Sombra Ecuador 2014, p. 45.

88 Ibid., pp. 46-48; P. Palacios Jaramillo, art. cit. 
comunidades rurales dependientes de la agricultura de subsistencia, también afecta especialmente a las mujeres, ya que son ellas las que realizan el trabajo no remunerado en la tierra, el ámbito doméstico y la producción de alimentos. ${ }^{89}$

En Ecuador, la aplicación de la visión del Buen Vivir supone, además de avances en cuanto al acceso a la tierra de las mujeres e incorporación al ámbito productivo, el reconocimiento y valorización del trabajo reproductivo, que pasa a incluirse además en la Seguridad Social. Cabe destacar la introducción de la Ley de Justicia Laboral y Reconocimiento del Trabajo No Remunerado del Hogar, que ha incorporado al Instituto Ecuatoriano de Seguridad Social (IESs) a 500000 mujeres dedicadas al cuidado del hogar a las que se garantiza una pensión. ${ }^{90}$ Según la Encuesta del Uso del Tiempo 2012, persistía una importante desigualdad en este ámbito: los datos reflejaban que las mujeres destinan el $52.2 \%$ de su tiempo al trabajo remunerado y el $47.5 \%$ al trabajo no remunerado, mientras que los hombres invierten el $78.6 \%$ de su tiempo al trabajo remunerado y tan sólo el $21.4 \%$ al trabajo no remunerado. ${ }^{91}$

El Bono de Desarrollo Humano, destinado a representantes de familias bajo la línea de pobreza, se asigna mayoritariamente a mujeres, quienes tienen que garantizar la asistencia regular de sus hijos menores de 6 años a los establecimientos de salud y a la escuela el $90 \%$ de los días de clases. Al otorgar estas responsabilidades a las mujeres, el Estado refuerza los roles de género e impone una doble carga sobre aquellas que trabajan también en el campo y el mercado productivo. ${ }^{92}$

\section{Conclusiones}

En cuanto al reconocimiento destacan Bolivia y Ecuador, donde los procesos constituyentes han permitido la participación de una

89 Ibid., p. 60.

90 "Ecuador reconoce el trabajo en el hogar y brinda Seguridad Social y pensiones", La República, 27 de octubre de 2015.

${ }^{91}$ Informe Sombra Ecuador 2014, pp. 46-48.

92 Ibid., p. 59. 
diversidad de ACM: REMTE, Frente Ecuatoriano de DS-DR (Ecuador), movimientos de mujeres indígenas en ambos casos y la Asamblea Feminista de Bolivia o Mujeres Creando Comunidad (Bolivia). Esta participación institucional ha permitido la inclusión de perspectivas feministas en sus respectivas constituciones y una valorización de la economía del cuidado y el trabajo reproductivo en los textos constitucionales. Sin embargo, por lo que hace al discurso, estos logros se diluyen, aún más en la práctica, al primar creencias religiosas y valores conservadores. La imposición unilateral de estos valores contrasta no sólo con la laicidad del Estado y las nuevas constituciones, sino también con la supuesta apertura de estos procesos a la participación directa de la ciudadanía y los movimientos sociales. También observamos que los logros normativos en los ámbitos de violencia de género, derechos sexuales y reproductivos y derechos de las mujeres indígenas pierden efectividad en su implementación. La participación en los procesos de la ACM ha sido efectivamente exitosa jurídica y normativamente; sin embargo es preocupante que esto no se convierta en avances prácticos. La autonomía de estos movimientos permite que esta falta de efectividad se denuncie a pesar de su participación en el proceso, pero vemos que la confrontación con el Frente Ecuatoriano, por ejemplo, limita la incidencia institucional y política de la organización.

En el caso de Cuba, el reconocimiento se ha referido a la emancipación de las mujeres en un proyecto más amplio de transformación socialista, con un importante avance en cuanto a derechos sexuales y reproductivos. Sin embargo, la falta de reconocimiento del feminismo se refleja en cuestiones tan básicas como la implementación de leyes específicas y protocolos de actuación en lo que atañe a la violencia de género. El estrecho vínculo de la FMC con el aparato estatal ha permitido el reconocimiento de las mujeres en el ámbito público y la garantía de los derechos reproductivos. El carácter de movimiento dirigido de la FMC, sin embargo, ha impedido reflexiones y actuaciones independientes de la visión estatal sobre política de género, al ser necesaria la incorporación de una perspectiva feminista para el avance en ámbitos fundamentales. Esto ha afectado en el pasado la posible aparición de otros colectivos feministas con visiones distintas sobre política de género, 
cuestión que, sin embargo, se ha puesto precisamente sobre la mesa al hilo de las reflexiones que se están dando en la Isla desde 2008.

Cabe señalar que si bien en Bolivia y Ecuador la trayectoria de los movimientos de mujeres ha ido acorde al activismo feminista transnacional, no ocurrió así en Cuba y en el periodo de mayores transformaciones entre 1960 y la década de los setenta no se dio la relevancia a la discriminación en el ámbito privado que se estaba teorizando en el resto del mundo. Sin embargo, esto ha ido cambiando y actualmente las principales reivindicaciones feministas en la Isla se relacionan con cuestiones tratadas especialmente en Latinoamérica, de entre las que destacan, por ejemplo, la violencia machista y la inclusión del "feminicidio" en el Código Penal.

La representación también ha sido afectada por la falta de reconocimiento del feminismo en el caso de Cuba y por la contradicción entre teoría y práctica en Ecuador y Bolivia. Si bien hay que subrayar el logro de importantes avances en cuanto a la incorporación de las mujeres en órganos de decisión, en Cuba esto no se ha reflejado particularmente en los máximos cargos de poder. Pero destaca, sobre todo, que en ninguno de los casos esto implica necesariamente la aplicación de una política efectiva de género, ya que se mantiene una visión patriarcal en el ejercicio del poder. Además persiste en Bolivia y Ecuador una violencia política y simbólica para con las mujeres en las instituciones.

En cuanto a la redistribución, se han tenido éxitos importantes en los tres casos por la atención que estos procesos han puesto en políticas contra la pobreza y desigualdad. Hay que destacar las medidas legislativas sobre trabajo reproductivo en Ecuador. Con todo, y a pesar del compromiso con la redistribución del trabajo reproductivo en los textos constitucionales en Bolivia y Ecuador, este mecanismo, así como las medidas contra la pobreza, se ha implementado de forma tal que se refuerzan estereotipos de género, promoviendo el confinamiento de las mujeres al ámbito doméstico. En Cuba tampoco se está tomando en cuenta la perspectiva de género en las reformas socioeconómicas introducidas por el gobierno de Raúl Castro. Llama la atención que en todos los casos persiste una división sexual del trabajo, que propicia la depauperación de las mujeres y la feminización de la pobreza. 
Como decía Molyneux, se observa que la redistribución resulta ser la dimensión en la que existe una menor efectividad, especialmente respecto a la división sexual del trabajo. A pesar de que procesos de carácter progresista como los analizados prestan particular atención a la redistribución, que afecta positivamente a grupos vulnerables como las mujeres, resulta más complicada la efectiva implementación de políticas de redistribución con perspectiva de género. Los casos examinados demuestran, en fin, que la falta de redistribución está relacionada con la falta de reconocimiento y representación real del feminismo. En Bolivia y Ecuador, se pone de manifiesto que el reconocimiento ya político, ya jurídico, debe ir de la mano de una implementación efectiva de políticas de género y un reconocimiento real de la desigualdad y discriminación de género en todas las instancias gubernamentales y órganos de representación.

\section{BibLIOGRAFÍA}

Agreda, Evelyn, "Del proceso Constituyente al Vivir Bien desde la mirada de las mujeres", en Mujeres en diálogo: avanzando hacia la despatriarcalización, La Paz, Coordinadora de la Mujer, 2012.

Alfonso González, Georgina, "Desafíos del feminismo socialista en la Cuba actual", América Latina en Movimiento. Feminismo popular para cambiar el mundo, núm. 489, 2013, pp. 20-22.

Álvarez, Sonia, Engendering democracy in Brazil. Women's movements in transition politics, Princeton, University Press, 1990.

Bringel, Breno y María Almudena Cabezas, "Geopolítica de los movimientos sociales latinoamericanos: espacialidades, ciclos de contestación y horizonte de posibilidades", en Anuario de la integración latinoamericana y caribeña 2011, Nueva Orleans, University Press of the South-Ediciones de la Noche, 2014, pp. 323-342.

Cabezas Fernández, Marta, "De orgánicas e invitadas: una mirada a la participación de las mujeres en la bancada del Movimiento al Socialismo (2006-2008)", Umbrales (Género y desafíos post-neoliberales), núm. 18, 2008, pp. 236-264. 
Cabezas González, María Almudena, "Anotaciones sobre el tejido feminista latinoamericano: más allá de las genealogías”, Contextualizaciones Latinoamericanas, año 6, núm. 11, 2014, pp. 1-9.

Cubanas en el vórtice del empleo, La Habana, SEMLAC, 2015.

Federici, Silvia, Revolución en punto cero. Trabajo doméstico, reproducción y luchas feministas, Madrid, Traficantes de Sueños, 2013.

__, "Salarios contra el trabajo doméstico" (1975), en Silvia Federici, Revolución en punto cero. Trabajo doméstico, reproducción y luchas feministas, Madrid, Traficantes de Sueños, 2013, pp. 35-44.

y Nicole Cox, "Contraatacando desde la cocina" (1975), en Silvia Federici, Revolución en punto cero. Trabajo doméstico, reproducción y luchas feministas, Madrid, Traficantes de Sueños, 2013, pp. 51-70.

Fraser, Nancy, Fortunes of feminism. From state-managed capitalism to neoliberal crisis, Londres, Verso, 2013.

Fuentes, Marta, "Feminismo y movimientos populares en América Latina”, Nueva Sociedad, núm. 118, 1992, pp. 55-60.

Gargallo, Francesca, Feminismos de Abya Yala. Ideas y proposiciones de las mujeres de 607 pueblos en Nuestra América, México, Editorial Corte y Confección, 2014.

Halliday, Fred, Revolution and world politics. The rise and fall of the sixth great power, Hampshire, Palgrave Macmillan, 1999.

Hernández Hormilla, Helen, "Más vulnerables ante la reforma económica", en Cubanas en el vórtice del empleo, La Habana, SEMLAC, 2015, pp. 8-11.

Jaquette, Jane S., "Women in Revolutionary Movements in Latin America", Journal of Marriage and the Family, vol. 35, núm. 2, 1973, pp. 344-354.

-, "The Women's Movement in Latin America: Feminism and the Transition to Democracy”, Bulletin of Latin American Research, vol. 9, núm. 2, 1990, pp. 291-293;

, "Introduction: from transition to participation - Women's movements and democratic politics", en Jane S. Jaquette (ed.), The women's movements in Latin America. Participation and democracy, Boulder, Westview Press, 2a ed., 1994, pp. 1-12.

-, The women's movements in Latin America. Participation and democracy, Boulder, Westview Press, 1994.

León, Irene, "Ecuador: la tierra, el Sumak Kawsay y las mujeres", en Sumak Kawsay/Buen Vivir y cambios civilizatorios, Quito, FEDAEPs, 2a ed., 2010, pp. 143-153. 
León, Magdalena, "Después del «desarrollo»: el «buen vivir» y las perspectivas feministas para otro modelo en América Latina", Umbrales (Género y desafíos post-neoliberales), núm. 18, 2008, pp. 35-44.

Luna, Lola G., "Género y movimientos sociales en América Latina”, Boletín Americanista, núms. 39/40, 1989-1990, pp. 131-141.

Macías Amores, Joseba, La sociedad civil en la Revolución cubana (1959-2012), Leioa, Universidad del País Vasco/Euskal Herriko Unibertsitatea, 2016. , "Revolución Cubana: Mujer, Género y Sociedad Civil", Viento Sur, 2 de marzo de 2011.

Martí i Puig, Salvador y Cristina Bastidas, “¿Ha Cambiado la protesta? La coyuntura actual de movilizaciones en Bolivia y Ecuador", Iconos. Revista de Ciencias Sociales, núm. 44, 2012, pp. 19-33.

Miguel Álvarez, Ana de y Celia Amorós Puente (eds.), Teoría feminista: de la ilustración a la globalización. Del feminismo liberal a la posmodernidad, Madrid, Minerva Ediciones, 2010.

Molyneaux, Maxine, "Mobilization without emancipation? Women's interests, the state and revolution in Nicaragua", Feminist Studies, vol. 11, núm. 2, 1985, pp. 227-254.

-, Movimientos de mujeres en América Latina. Estudio teórico comparado, Madrid, Cátedra, 2003. Ed. original: Women's movements in international perspective. Latin America and beyond, Londres, Institute of Latin American Studies, 2001.

Moya, Isabel, "Alas desatadas", Intervención en el Seminario 50 Aniversario de la Revolución Cubana celebrado en La Habana, del 14 al 16 de julio de 2008, disponible en La Jiribilla, 3-9 de enero 2009.

Palacios Jaramillo, Patricia, "Los derechos de las mujeres en la nueva Constitución", Institute for Research and Debate on Governance, marzo de 2008.

Paredes, Julieta, Hilando fino desde el feminismo comunitario, La Paz, Mujeres Creando Comunidad-Deutscher Entwicklungdienst, 2010.

Perea Ozerin, Iratxe, Incidencia de las Revoluciones en los Movimientos Sociales Transnacionales. El caso de la Revolución Cubana y su influencia en el Movimiento Antiglobalización, tesis, Leioa, Universidad del País Vasco/ Euskal Herriko Unibertsitatea, 2014.

, "El papel del feminismo en el Movimiento Antiglobalización: contribuciones y desafíos", Revista CIDOB d'Afers Internacionals, núm. 105, 2014, pp. 67-88. 
Proveyer, Clotilde, "Violencia de género. Aproximación desde la realidad cubana”, Revista Sexología y Sociedad, vol. 20, núm. 1, 2014, pp. 3-17.

Puleo García, Alicia Heldo, "Lo personal es político: el surgimiento del feminismo radical", en Ana de Miguel Álvarez y Celia Amorós Puente (eds.), Teoría feminista: de la ilustración a la globalización. Del feminismo liberal a la posmodernidad, Madrid, Minerva Ediciones, 2010, pp. 35-68.

Rauber, Isabel, "Gobiernos populares en América Latina y el Caribe: ¿revoluciones o neorreformismo?”, Pasos, núm. 137, 2008, pp. 1-14.

Rodríguez Manzano, Irene, "Mujer, género y teoría feminista en las Relaciones Internacionales”, en Cursos de Derecho Internacional y Relaciones Internacionales de Vitoria-Gasteiz 2000, Leioa-Madrid, Universidad del País Vasco/Euskal Herriko Unibertsitatea-Tecnos, 2001, pp. 239-292, en http://www.ehu.es/cursosderechointernacionalvitoria/ponencias /pdf/2000/2000_6.pdf

Rowbotham, Sheila, Women in movement. Feminism and social action, Londres, Routledge, 1992.

Vargas, Virginia, "El movimiento de mujeres en el Perú: vertientes, espacios y nudos", en Feminismos en América Latina. Su aporte a la política y a la democracia, Lima, Programa Democracia y Transformación Global, Centro de la Mujer Peruana Flora Tristán y UNMSM, 2008.

—_ Feminismos en América Latina. Su aporte a la política y a la democracia, Lima, Programa Democracia y Transformación Global, Centro de la Mujer Peruana Flora Tristán y UNMSM, 2008

Vasallo Barrueta, Norma, Ecos distantes, voces cercanas, miradas feministas, La Habana, Editorial de la Mujer, 2012.

Ybarnegaray Ortiz, Jenny, "Un fallo engorroso y vocinglero", América Latina en Movimiento, 17 de febrero de 2014.

\section{OTRAS FUENTES DE DOCUMENTACIÓN}

Aguiñaga, Marcela, "La equidad de género en la cultura política", Asamblea Nacional República de Ecuador, 26 de junio de 2013.

"América Latina: feminismos en el camino de la emancipación", SEMLAC, 20 de enero de 2015.

Campoalegre Septien, Rosa, "Feminicidio: lo esencial no puede ser invisible", SEMLAC, 22 de mayo de 2016. 
Coalición Nacional de Mujeres para la Elaboración del Informe Sombra de la CEDAw, Informe Sombra al Comité de la CEDAw, Quito (Ecuador), noviembre de 2014.

Coalición de Organizaciones de Derechos Humanos de las Mujeres de la Sociedad Civil, "Contribuciones de la Coalición de Organizaciones de Derechos Humanos de las Mujeres de la Sociedad Civil para la elaboración de la Lista de Cuestiones sobre el quinto y sexto informe periódico estatal, para su adopción por el CEDAw", Bolivia, octubre de 2014.

Cobo, Diego, "Y el «cuentapropismo", ¿liberó a las mujeres?", Revista Pikara, 26 de febrero de 2014.

Confederación Nacional de Mujeres Indígenas de Bolivia, el Consejo Nacional de Ayllus y Markas del Qullasuyu y la Confederación Nacional de Pueblos Indígenas de Bolivia, Informe Sombra de las Mujeres de Naciones y Pueblos Indígenas de Bolivia, julio de 2015.

Constitución Política del Estado de Bolivia, 7 de febrero de 2009.

Constitución de la República del Ecuador, 20 de octubre de 2008.

“¿Cuánto ha cambiado Ecuador con la Revolución Ciudadana?”, Telesur, 24 de mayo de 2016.

"Ecuador reconoce el trabajo en el hogar y brinda Seguridad Social y pensiones", La República, 27 de octubre de 2015.

Edith, Dixie, "Cuba: feminismo sin etiqueta", Feminismo en Cuba, 20 de diciembre de 2010.

Estatutos del Partido Comunista de Cuba, en http://www.pcc.cu/pdf/ documentos/estatutos/estatutos6c.pdf

"Feminismo, un debate necesario para Cuba", SEMLAC, 16 de marzo de 2015.

"Gobierno de Evo Morales mejoró calidad de vida de bolivianos", Telesur, 2 de agosto de 2016.

Goldsman, Florencia, "Entrevista a Julieta Montaño", Revista Pikara, 2 de junio de 2015.

Gordillo Piña, Lirians, "Cambios imponen desafíos a las ciencias sociales”, SEMLAC, 19 de octubre de 2015.

_- "Feministas cubanas estrenan nuevo espacio de debate", SEMLAC, 9 de mayo de 2016.

Hernández Hormilla, Helen, "Mujeres también sufren violencia económica”, SEMLAC, 13 de abril de 2015 . 
Informe Central al VII Congreso del PCC, La Habana, 16 de abril de 2016. "Intervención del presidente de la República, Rafael Correa, en la ceremonia de inauguración de la Asamblea Nacional Constituyente", Montecristi, 30 de septiembre de 2007.

Mas, Sara, "Violencia de género. La ley no es suficiente", Rebelión, 8 de diciembre de 2011.

— - "Violencia de género. En busca de respuestas más efectivas", Rebelión, 27 de marzo de 2012.

— , "Urge protocolo de actuación frente a violencia de género", SEMLAC, 30 de marzo de 2016.

Plan Nacional para la Erradicación de la Violencia de Género (PNEVG), 10 de septiembre de 2007.

Plan V, "Plan Familia Ecuador o un retroceso de cien años", 14 de marzo de 2015.

"Rafael Correa amenaza con dimitir si se aprueba la despenalización del aborto", El Mundo, 11 de octubre de 2013.

"Rafael Correa rechaza la «absurda» y «peligrosísima» ideología de género", Infobae, 3 de enero de 2014.

Sánchez Jaramillo, Fernanda, "Entrevista a Julieta Paredes”, Rebelión, 19 de diciembre de 2014.

SEMLAC: Servicio de Noticias de la Mujer de Latinoamérica y el Caribe, en http://www.redsemlac.net/

"Violencia contra la mujer cobra este año 1800 vidas en América Latina", Cubadebate, 25 de noviembre de 2013. 